\title{
X-Ray-Free Endoscopic Combined Intrarenal Surgery for Complex Proximal Ureteral Stone: A Case Report
}

This article was published in the following Dove Press journal: Research and Reports in Urology

\section{Ponco Birowo (1D \\ Putu Angga Risky Raharja (D) \\ Widi Atmoko \\ Nur Rasyid (D)}

Department of Urology, Faculty of Medicine, Universitas Indonesia, Cipto Mangunkusumo Hospital, Jakarta, 10430, Indonesia
Correspondence: Ponco Birowo Department of Urology, Faculty of Medicine, University of Indonesia, Cipto Mangunkusumo Hospital, Jakarta, I0430, Indonesia

Tel +62213923631

Fax +6281213145592

Email ponco.birowo@gmail.com

\begin{abstract}
X-ray-free endoscopic combined intra renal surgery (ECIRS) is a feasible alternative to avoid radiation exposure to both surgical teams and patients, but has not been reported prior. The aim of this report is to present our first-hand experience of performing X-ray-free ECIRS for complex ureteral stone. A 57-year-old female presented with right flank pain, fever, dysuria, and leukocytosis. The computed tomography scan showed right impacted proximal ureteral stone sized 33 '17 mm and grade IV hydronephrosis. Percutaneous nephrostomy was performed immediately. With improvement of clinical symptoms two days after nephrostomy, X-ray-free ECIRS was performed. The patient was placed in a Galdakao-modified supine position. During ureteroscopy (URS), there was noted right ureteral stenosis in the distal part of the stone, which could be passed. However, the stone was impacted and the semi-rigid URS was not able to push it. Therefore, antegrade approach with percutaneous nephrolithotomy was performed. Previous nephrostomy tract was used as percutaneous access. Tract dilatation was performed under direct visualization from the URS. The $28 \mathrm{Fr}$ rigid nephroscope was used during the ECIRS procedure. The stone was fragmented using shock-pulse lithotripters. There was no residual stone or infundibular laceration after the procedure. A 6 Fr double $\mathrm{J}$ stent was inserted retrogradely due to ureteral stenosis. There was no complication during and after the procedure. The patient was discharged on postoperative day three. X-ray free ECIRS for complex proximal ureteral stone was possible and showed good results.
\end{abstract}

Keywords: ECIRS, supine position, ureterolithiasis, modified procedure

\section{Introduction}

Large stones in the upper urinary tract are frequently related to infection and obstruction. ${ }^{1}$ If left untreated, large renal and proximal ureteral stones may result to renal loss, sepsis, and even death. ${ }^{1}$ There are several modalities for management of proximal ureteral stones, such as extracorporeal shock wave lithotripsy (ESWL), ureteroscopy lithotripsy (URSL), percutaneous nephrolithotomy (PCNL), laparoscopy, and open surgery. ${ }^{2}$ However, the management for large impacted proximal ureteral stones remains challenging for urologists. ${ }^{3}$

Endoscopic combined intra renal surgery (ECIRS) is a new way of conducting PCNL in the supine position. ${ }^{4}$ It unites antegrade and retrograde approaches to the renal collecting system and aims for a single-access resolution of stones along the entire urinary tract. ${ }^{4}$ The integration of ureteroscopy in 
a combined antegrade and retrograde approach for complex proximal ureteral stones allows for direct visualization during antegrade tract dilatation and synergistic stone clearance with both the nephroscope and ureteroscope.

Although ECIRS is associated with reduced X-ray exposure, it is still performed under fluoroscopic guidance which may increase ionizing radiation hazard. ${ }^{4-6}$ $\mathrm{X}$-ray free ECIRS is a feasible alternative to avoid radiation exposure to both surgical teams and patients. We have reported our experience of performing this $\mathrm{X}$-ray free procedure in PCNL previously. ${ }^{7,8}$ The aim of this report is to present our first-hand experience of performing X-ray-free ECIRS in a case of complex ureteral stone. To our knowledge, this is the first report of such a case.

\section{Case Presentation}

A 57-year-old female was admitted to emergency room with a chief complain of worsening right flank pain since two days prior. The pain was not radiating and blunt in quality. It was accompanied by fever, dysuria, nausea, and vomiting. History of diabetes mellitus and hypertension were denied. From physical examination, there was right costovertebral angle tenderness during percussion. Laboratory examinations showed an increased white blood cell count (WBC) of $25.27^{\prime} 10^{3} / \mu \mathrm{L}$ with $89 \%$ neutrophil dominance, hemoglobin level of $11.3 \mathrm{~g} / \mathrm{dL}$, and increased creatinine level of $1.82 \mathrm{mg} / \mathrm{dL}$. Urinalysis revealed $50-100 \mathrm{WBC} / \mathrm{high}$ power field (HPF), 2-5 red blood cells (RBC)/HPF, and positive test for leukocyte esterase and bacteria. A noncontrast CT scan revealed right grade IV hydronephrosis due to right proximal ureteral stone sized $33^{\prime} 17 \mathrm{~mm}$ (Figure 1). We gave intravenous levofloxacin at $750 \mathrm{mg}$ daily and performed emergency percutaneous nephrostomy. Nephrostomy was performed under ultrasound guidance into the medial calyx. Clinical symptoms and laboratory parameters improved after the procedure. We elected to perform x-ray-free ECIRS two days after nephrostomy procedure for this patient.

\section{Ureter Evaluation from the CT Scan}

We made careful assessment of the right ureter using the CT scan. There was no significant kinking of right ureter. There was right impacted proximal ureteral stone sized $33^{\prime} 17 \mathrm{~mm}$. There was possibility of right ureteral stenosis in the distal part of the stone and hydroureter in the proximal part of the

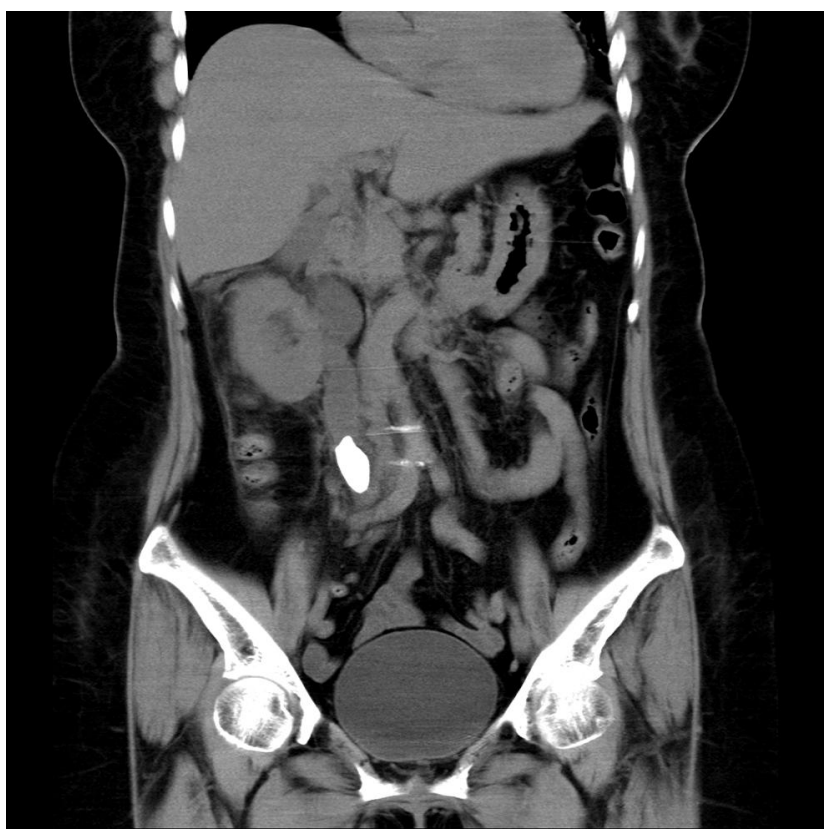

Figure I CT-scan showing right proximal impacted ureteral stone sized $33 \times 17 \mathrm{~mm}$.

stone (Figure 2). Since there was both a stone and stenosis in the right ureter, the insertion of the guide-wire was planned as URS-guided without fluoroscopy assistance.

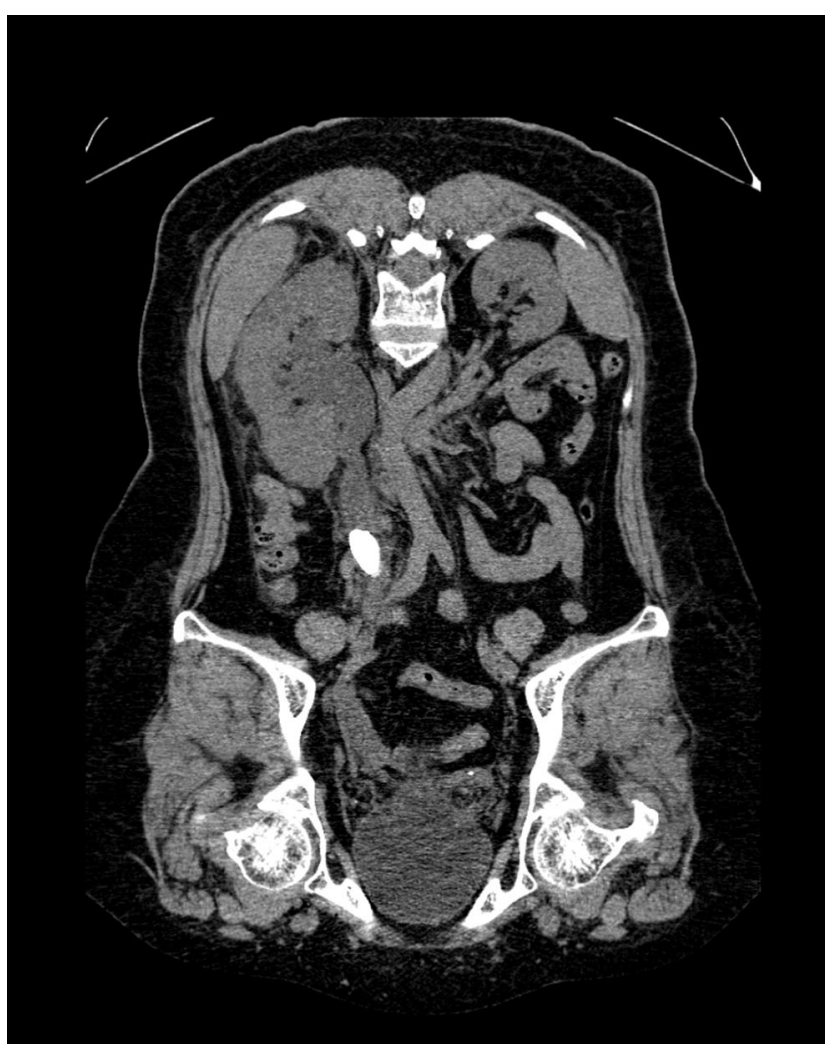

Figure 2 Coronal plane view of the right ureter showing possibility of stenosis in the distal part of the stone and hydroureter in the proximal part of the stone. 


\section{Ureteroscopy Evaluation and Placement of Guide-Wire}

The patient was placed in a Galdakao-modified supine Valdivia position. A 6 Fr semi-rigid URS sheath (Ultrathin ${ }^{\mathrm{TM}}$, Richard Wolf Ureteroscopes, Vernon Hills IL, USA) was inserted into the right ureteral orifice. There was noted right ureteral stenosis in the distal part of the stone (Figure 3A). However, the URS sheath could be advanced through the stenosis and the ureteral stone was visualized soon after (Figure 3B). However, the ureteral stone was impacted and could not be pushed back into the right collecting system with URS sheath. However, there was an opening that allowed the URS sheath to be advanced through the side of the stone. A nephrostomy pigtail catheter (Renodrain Yellow/7 Fr, Urotech, Franklin, TN, USA) was visualized via URS. We inserted a guidewire (zebra nitinol guidewire, $3 \mathrm{~cm}$ angled-tip, size 0.035 in ' $150 \mathrm{~cm}$, Boston Scientific, Boston, MS, USA) towards the right collecting system from the nephrostomy pigtail catheter (Figure 4A). The guide-wire was taken out with forceps to the urethra for safety reasons (Figure 4B). After placement of guidewire, the nephrostomy pigtail catheter was then removed.

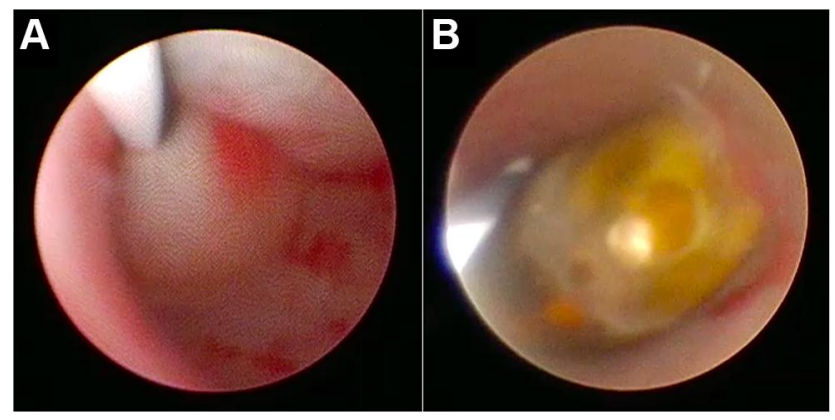

Figure 3 (A) Ureteral stenosis in the distal part of the stone from URS visualization; (B) right proximal ureteral stone from URS visualization.

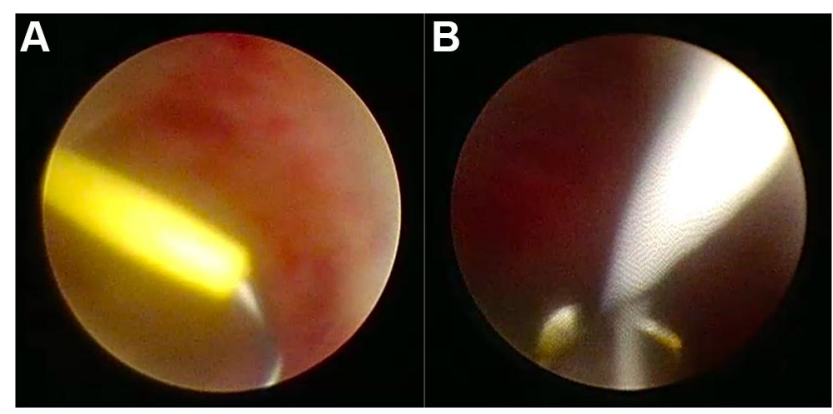

Figure 4 (A) Guide-wire insertion from the nephrostomy tube into the collecting system; (B) guide-wire was taken out with forceps for safety reasons.

\section{Visualization of Tract Dilatation with Ureteroscopy}

Instead of making new puncture site for kidney access, we used the previous nephrostomy tract. An additional $1 \mathrm{~cm}$ transverse incision was made in the skin to allow insertion of $28 \mathrm{Fr}$ Amplatz sheath (Olympus America, Center Valley, PA, USA). Kidney dilatation was performed with Alken metal telescoping dilators $\left(6 \mathrm{Fr}^{\prime} 30 \mathrm{Fr}\right)$ under direct visualization from the URS (Figure 5A). A $28 \mathrm{Fr} / 17 \mathrm{~cm}$ Amplatz sheath was also placed under direct visualization from the URS (Figure 5B). The total tract dilatation time (time from advancement of Alken metal telescoping dilators to advancement of the Amplatz sheath) was 1.1 minutes.

\section{Stone Fragmentation and Evacuation}

The 28 Fr rigid nephroscope (Olympus high-flow rigid nephroscope, Olympus America, Center Valley, PA, USA) was used during our ECIRS procedure. The stone was identified and then fragmented with a 3.78 Fr shock-pulse lithotripters (Olympus ShockPulse-SE, Olympus America, Center Valley, PA, USA) (Figure 6A). The stone fragments were then evacuated using stone forceps (Figure 6B). During this part procedure, we ensured no residual stone or infundibular laceration, as confirmed via nephroscope evaluation (Figure 6C). We decided to insert $6 \mathrm{Fr}$ double $\mathrm{J}$ (DJ) stent retrogradely with guide-wire assistance, since there was stenosis in the right ureter (Figure 6D).

The total surgical time was 95 minutes. Blood loss during the procedure was $50 \mathrm{~mL}$. There was no significant complication during and after the procedure. Evacuated stone fragments are shown in Figure 7A. Post-operative laboratory parameters were: hemoglobin level of $11.8 \mathrm{mg} / \mathrm{dL}$, WBC level of $7.71^{\prime} 10^{3} / \mu \mathrm{L}$, and creatinine level of $0.81 \mathrm{mg} / \mathrm{dL}$. Post-operative kidney ureter bladder

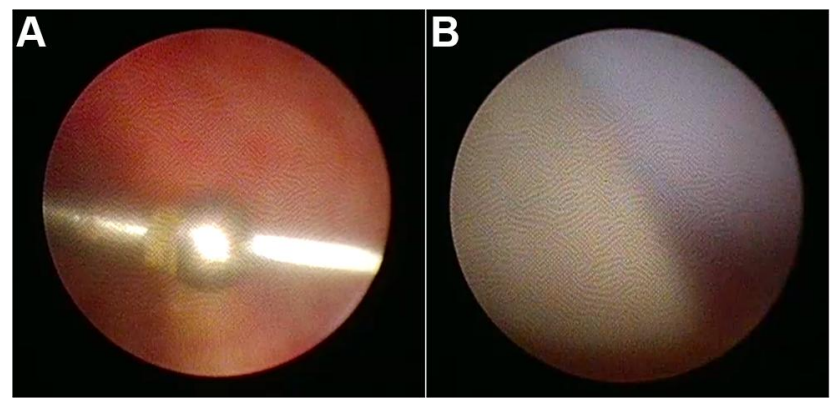

Figure 5 (A) Direct visualization of kidney dilatation with Alken metal telescoping dilators; (B) direct visualization of Amplatz sheath advancement. 


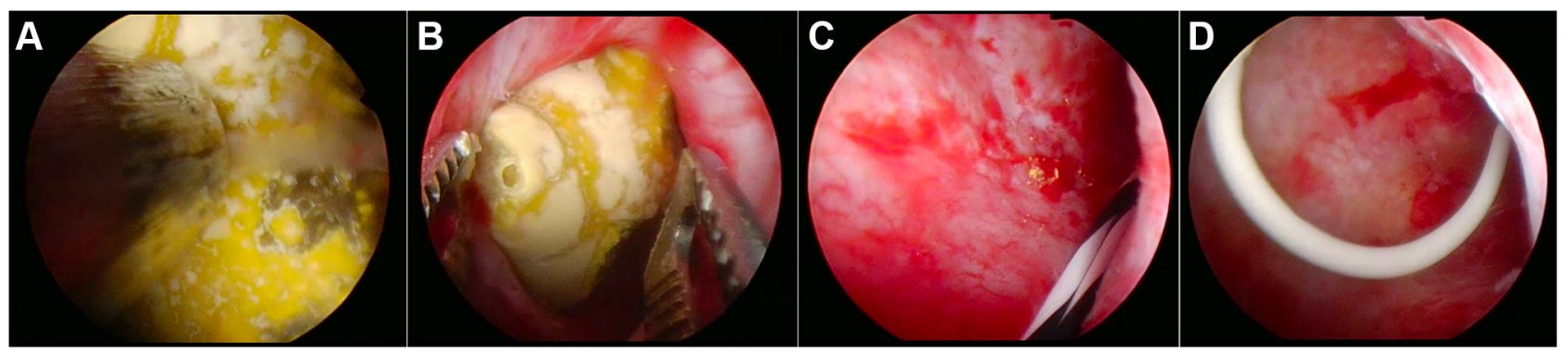

Figure 6 The stone was fragmented with shock-pulse lithotriptor $(\mathbf{A})$ and taken out with stone forceps $(\mathbf{B})$. There was no residual stone after the procedure (C). A 6-Fr DJ stent was inserted retrogradely (D).
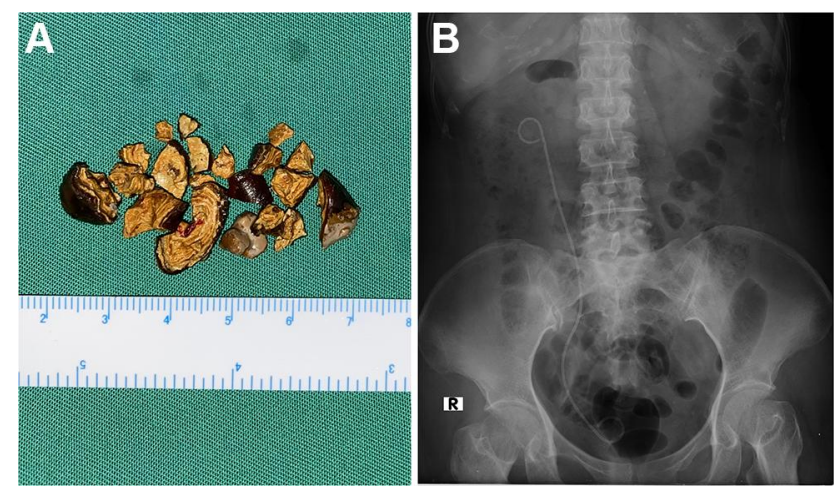

Figure 7 (A) Evacuated stone fragments during the procedure; (B) post-operative KUB photo showing no residual stone in the right kidney with correctly-positioned DJ stent.

(KUB) photo showed no residual stone with a correctlypositioned DJ stent (Figure 7B). Previous urine culture result showed growth of Escherichia coli bacteria and sensitive to levofloxacin, therefore intravenous levofloxacin at $750 \mathrm{mg}$ daily was continued after the procedure. The patient was discharged stable on post-operative day three.

Written informed consents for publication of clinical details and any accompanying images were obtained from the patient. The Ethics Committee of the Faculty of Medicine, Universitas Indonesia approved the study protocol (KET-1388/UN2.F1/ETIK/PPM.00.02/2020).

\section{Discussion}

The first-line treatment for a large impacted proximal ureteral stone is small-caliber semi-rigid or flexible ureteroscopes combined with holmium laser. ${ }^{9}$ However, retrograde access may be difficult due to inflammation, edematous mucosa, or a fibroepithelial polyp often found enveloping the impacted stone, which may impede exposure and lithotripsy. ${ }^{3}$ Therefore, an antegrade approach is sometimes required for management of complex stone. This case report highlights the possibility of performing
ECIRS, which combines both antegrade and retrograde approaches, for complex impacted proximal ureteral stone.

Performing x-ray-free ECIRS have several advantages, namely anesthesiologic, urologic, and management advantages. ${ }^{6}$ For anesthesiologic advantages, the ECIRS procedure in our case allowed it to be performed in a Galdakao-modified supine Valdivia position. This position is correlated with less cardiovascular, respiratory, neuroendocrine, and pharmacokinetic problems compared to prone position. ${ }^{10}$ As urological advantages, ECIRS allows for direct visualization during antegrade tract dilatation and synergistic stone clearance. ${ }^{6}$ Endoscopic supervision for each step of the renal access will reduce the risk of infundibular laceration during the process, or even colon injury. ${ }^{6}$ Performing x-ray-free ECIRS will also avoid radiation hazard to both the patient and operating teams. This procedure could also be performed in centers with no access to fluoroscopy. As for management advantages, ease of patient positioning with no need for intraoperative position changes, reduced risk of pressure damages, and single sterile draping are features of ECIRS procedure.

Compared to conventional procedure, $x$-ray-free ECIRS also had several disadvantages. ECIRS procedure needs more equipment, including instruments and the monitor tower system. ${ }^{6}$ Therefore the cost of performing ECIRS procedure are more expensive. This procedure also requires two urologists to perform simultaneous antegrade PCNL and retrograde ureteroscopy. ${ }^{6}$ However, in an academic setting, the assistance of a resident to perform retrograde ureteroscopy during ECIRS could be a valuable occasion for teaching this technique as well as PCNL steps. ${ }^{6}$ In our case, retrograde ureteroscopy was performed by resident. In our case, entry points of dilators during endoscopic supervision were not visualized. Using flexible URS instead of semirigid URS could overcome this limitation. 
To our knowledge, there is no prior study that compares the stone-free rate of ECIRS procedure with other techniques for proximal ureteral stone. However, synergistic clearance and evaluation with both nephroscope and ureteroscopy will result in higher stone-free rate. In our case, the patient was stone-free after the procedure, which was confirmed by both intra-operative evaluation and postoperative KUB.

In the literature, ECIRS doubles the possibility of complications and morbidity by combining the risks of performing PCNL with the risks of performing ureteroscopy (complication rate of $1.5-12 \%$ in the literature). ${ }^{4}$ However, careful selection and preparation of patients are very important to reduce complications. ${ }^{4}$ In our case, there was no significant complication during and after the procedure, The patient was discharged on post-operative day three.

\section{Conclusion}

X-ray-free ECIRS for complex proximal ureteral stone was performed successfully and showed good results. The patient was stone-free after the procedure with no significant complications. X-ray-free ECIRS may be an option that decreases anesthesia and radiation risks while giving greater assurance of stone-free status intraoperatively in select patients.

\section{Data Sharing Statement}

All data underlying the results are available as part of the article and no additional source data are required.

\section{Author Contributions}

All authors made a significant contribution to the work reported, whether that is in the conception, study design, execution, acquisition of data, analysis and interpretation, or in all these areas; took part in drafting, revising or critically reviewing the article; gave final approval of the version to be published; have agreed on the journal to which the article has been submitted; and agree to be accountable for all aspects of the work.

\section{Funding}

There is no funding to report.

\section{Disclosure}

The authors report no conflicts of interest in this work.

\section{References}

1. Cohen J, Cohen S, Grasso M. Ureteropyeloscopic treatment of large, complex intrarenal and proximal ureteral calculi. BJU Int. 2013;111:1-5. doi:10.1111/j.1464-410X.2012.11352.x

2. Mousavi Bahar SH, Amirhassani S, Nouralizadeh A, ZerafatJou N, Rasiuli J. Percutaneous nephrolithotomy versus laparoscopy in the management of large proximal ureteral stones: the experience of two different settings. Urol J. 2019;16:448-452. doi:10.22037/uj. v0i0.4538

3. Xiao-jian G, Jian Lin L, Yan X. Treatment of large impacted proximal ureteral stones: randomized comparison of minimally invasive percutaneous antegrade ureterolithotripsy versus retrograde ureterolithotripsy. World J Urol. 2013;31:1605-1610. doi:10.1007/ s00345-013-1026-2

4. Cracco CM, Scoffone CM. ECIRS (Endoscopic Combined IntraRenal Surgery) in the Galdakao-modified supine Valdivia position: a new life for percutaneous surgery? World $J$ Urol. 2011;29:821-827. doi:10.1007/s00345-011-0790-0

5. Scoffone CM, Cracco CM, Cossu M, Grande S, Poggio M, Scarpa RM. Endoscopic combined intrarenal surgery in Galdakao-Modified supine Valdivia position: a new standard for percutaneous nephrolithotomy? Eur Urol. 2008;54:1393-1403. doi:10.1016/j.eururo.2008.07.073

6. Scoffone CM, Cracco CM. Invited review: the tale of ECIRS (Endoscopic Combined IntraRenal Surgery) in the Galdakao-modified supine Valdivia position. Urolithiasis. 2018;46:115-123. doi:10.1007/s00240-017-1015-9

7. Birowo P, Raharja PAR, Putra HWK, Rustandi R, Atmoko W, Rasyid N. X-ray-free ultrasound-guided percutaneous nephrolithotomy in supine position using alken metal telescoping dilators in a large kidney stone: a case report. Res Rep Urol. 2020;12:287-293. doi:10.2147/RRU.S259941

8. Birowo P, Raharja PAR, Putra HWK, Rustandi R, Atmoko W, Rasyid N. X-ray-free ultrasound-guided versus fluoroscopy-guided percutaneous nephrolithotomy: a comparative study with historical control. Int Urol Nephrol. 2020;52:2253-2259. doi:10.1007/s11255020-02577-w

9. Preminger GM, Tiselius H-G, Assimos DG, et al. 2007 guideline for the management of ureteral calculi. J Urol. 2007;178:2418-2434. doi:10.1016/j.juro.2007.09.107

10. Ibarluzea G, Scoffone CM, Cracco CM, et al. Supine Valdivia and modified lithotomy position for simultaneous anterograde and retrograde endourological access. BJU Int. 2007;100:233-236. doi:10.1111/j.1464-410X.2007.06960.x
Research and Reports in Urology

\section{Publish your work in this journal}

Research and Reports in Urology is an international, peer-reviewed, open access journal publishing original research, reports, editorials, reviews and commentaries on all aspects of adult and pediatric urology in the clinic and laboratory including the following topics: Pathology, pathophysiology of urological disease; Investigation and treatment of urological disease; Pharmacology of drugs used for the treatment of urological disease. The manuscript management system is completely online and includes a very quick and fair peer-review system, which is all easy to use. Visit http://www.dovepress.com/ testimonials.php to read real quotes from published authors. 